\title{
An Application of Timmons Model in the Mini Entrepreneurial Logistics Project
}

\author{
Wee Yu Ghee \\ Malaysian Graduate School of Entrepreneurship and Business \\ Universiti Malaysia Kelantan
}

\begin{abstract}
The students of the Faculty of Entrepreneurship and Business, Universiti Malaysia Kelantan pursued a subject known as Trade Logistics and Distribution. As part of the course assessment, students were divided into groups and each group was required to implement a mini business project in the field of entrepreneurial logistics. They were free to work on any kind of business along the logistics chain, ranging from suppliers, distributors, manufacturers, wholesalers, retailers to consumers. This paper aimed to trace the application of Timmons Model of the Entrepreneurial Process by students during mini business project implementation. Findings show that students perceived resource availability as highly important in ensuring the success of the given project, and this is followed by the need for creativity and leadership quality. Correlation analysis indicates that creativity is significantly related to leadership quality, teamwork, resources available and opportunity identified. Leadership quality was also found to have influence on resource availability. Therefore, this study proves the relevancy of Timmons Model of the Entrepreneurial Process which implies that the key to any business success lies with the entrepreneur.
\end{abstract}

Field of research: Entrepreneurship, logistics, business management

\section{INTRODUCTION}

Universiti Malaysia Kelantan (UMK) is the first university in Malaysia which sets entrepreneurship as its main thrust. Established on 1 July 2007, this entrepreneurial university spells its vision as follows: to spearhead the development of enterprising human capital for social and economic well being of the nation. To date, UMK has nearly 10,000 students pursuing courses related to entrepreneurship. While students major in niche specialization such as tourism entrepreneurship, agro-entrepreneurship, health-entrepreneurship and many more, the ultimate aim of UMK is to produce not only graduate entrepreneur but graduates who are enterprising, be it in the context of serving the humanities (i.e. social entrepreneurship) or being creative and innovative during their tenure in large corporations (corporate entrepreneurship). To realize these objectives, all academicians take the responsibility to teach theories in entrepreneurship, and most importantly the tacit knowledge of how to be a successful entrepreneur. This research study was mooted out based on such rationale.

Jeffery Timmons of Babson College in Massachusetts developed the Timmons Model of Entrepreneurship as his doctorate thesis at Harvard University (Timmons, Zacharakis \& Spinelli, 2004). Based on this noble work, more interests were spurred among the researchers in the field of entrepreneurial process. Many research and case studies were written to enhance his model, as a guide for entrepreneur to increase the likelihood of success in business. As shown in Figure 1, the Timmons Model of Entrepreneurship Process considers opportunities, teams and resources as the three critical factors available to an entrepreneur 
and concludes that success depends on the ability of the entrepreneur to balance these critical factors.

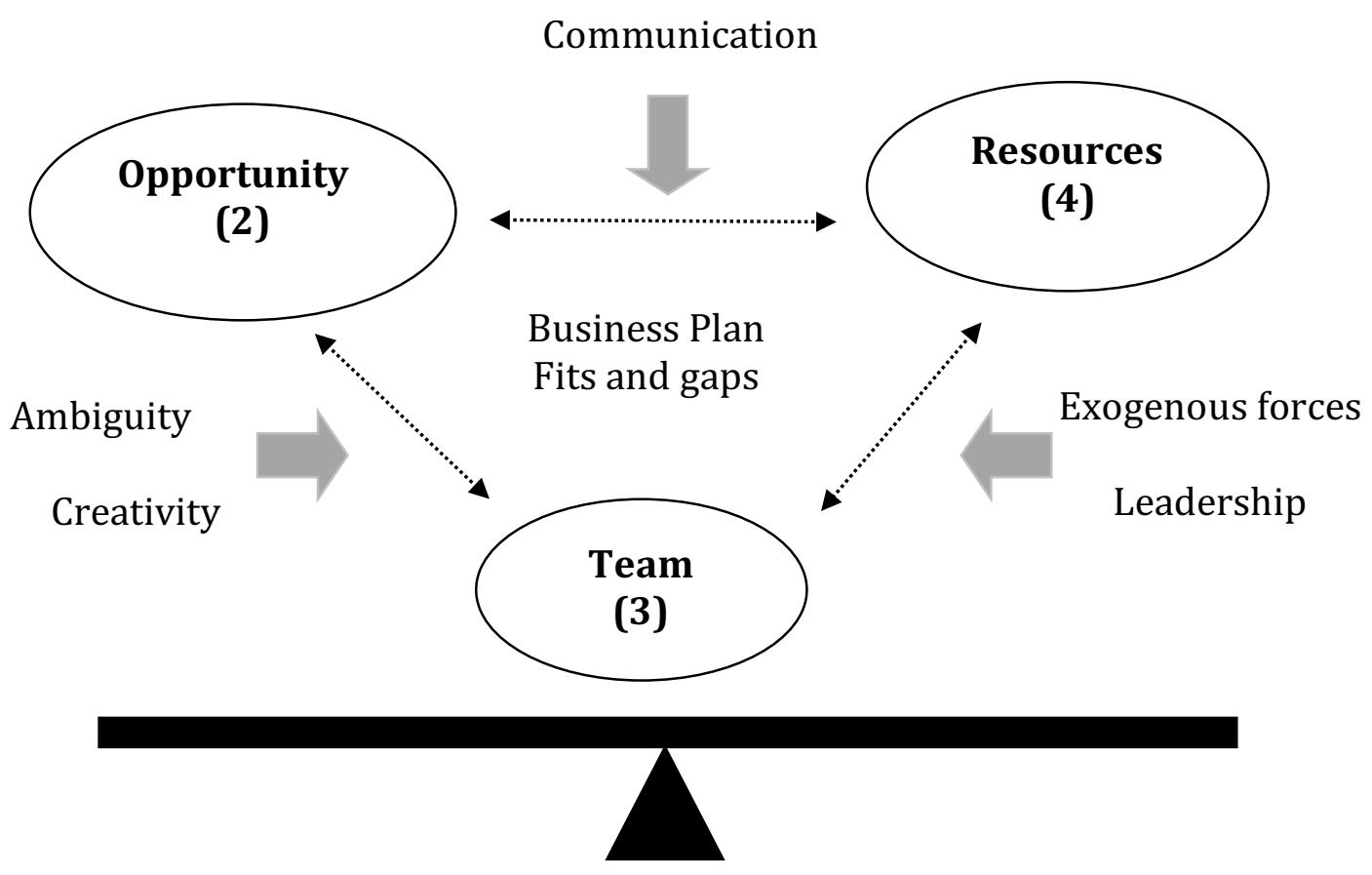

Founder (1)

Figure 1 The Timmons Model of the Entrepreneurial Process

A group of UMK students who were pursuing the subject of Entrepreneurial Logistics in September 2017 were given a task to relate this model in their mini business project they worked on in group basis. Upon the completion of the business project, these students were asked to evaluate on how effective and relevant Timmons Model was in ensuring the success of the business. This research study aims to answer two major objectives: (1) to identify factors which are perceived to be important by entrepreneurial students of UMK after their hands-on experience in mini business project, and (2) to examine if there exists any significant relationship among the factors perceived by these students.

\section{LITERATURE REVIEW}

According to Timmons, Zacharakis and Spinelli (2004), the key factors to entrepreneurial success lies with the entrepreneur, the founding team, the opportunity, and the resources that are mustered to start the new organization. In another words, Timmons model takes a normative approach. Timmons et al. (2004) affirm that the key ingredient is the entrepreneur. If the entrepreneur is equipped with the right skills and knowledge, he will be able to pull the right people together (founding team), search for relevant and ample resources (resources) to tackle the opportunity he sees in the market, shapes it well and turns it into potential business venture. Significantly, Timmons et al. (2004) proposed an integrated model, offering holistic balance and juggling act to how we should comprehend the entrepreneurial process and getting the odds in own's favour. The following questions are popular among the entrepreneur-to-be and even entrepreneurs running their business: "How to ensure the success of my business? How to make sure I do not fail? How successful is my success? How to maintain my business and entice further growth?" The answers to these questions, according to Timmons, boil down to this: a core, fundamental entrepreneurial process which accounts for 
the substantially higher success pattern among higher potential ventures; and the driving forces which gear for value creation are as follows:

- It is Opportunity driven;

- It is driven by Lead Entrepreneur and an Entrepreneurial Team;

- It is Resource Parsimonious and Creative;

- It depends on the Fit and Balance among these;

- It is Integrated and Holistic.

These controllable components of the entrepreneurial process can be assessed, influenced, moulded and altered, thereby allowing entrepreneurs to change the risk-to-reward equation into a positive and favourable manner. In other words, Timmons model bases itself on the entrepreneur. The entrepreneur looks for opportunity, mould the opportunity into highpotential business venture by teaming up with great talents; while pulling in all the required resources to start a business that capitalizes on the opportunity. In the process of starting the business, the entrepreneur places high risks on his self-employed career, personal cash flow and net worth (Nayab, 2010). Rewards will be earned by the entrepreneur if he manages the risk well and coordinate the efforts involved in starting or financing the business.

\section{Three critical factors: Opportunity, resources and team \\ Opportunity}

Contrary to many, Timmons model dictates that the entrepreneurial process does not start with business plan, money, strategy, networks or team. The Timmons model believes strongly that entrepreneurship is nothing but opportunity driven. Opportunities are more essential than the talent or competence of lead entrepreneur and the team because a right opportunity identified ensures long-term success of the business. The lead entrepreneur and team should play roles in juggling all the key elements well in a constantly changing and dynamic environment. A good idea does not necessarily bring about a great business because market demand determines the potential of the idea. An excellent idea is found when the product or service could be positioned to create or add values to consumers, remains attractive, durable and timely. And needless to say, only such great opportunity has no difficulties in financing the business project. In fact, for every 100 ideas presented to investors in the form of a business plan or proposal of some kind, usually just 1 or sometimes 2 or 3 get funded. Over $80 \%$ of these are rejected in the first few hours; another $10 \%$ to $15 \%$ are rejected after investors have read the business plan carefully. Less than $10 \%$ attract enough interest to merit thorough due diligence and investigations over several weeks and even months. Entrepreneurs have been wasting time and resources running after business ideas which get them nowhere (Doerr, 1997).

\section{Resources}

According to Timmons Model, one of the misconceptions among inexperienced entrepreneurs is that you must first have all the resources in place, especially money, in order to succeed in a venture. Surprisingly and ridiculously as it may sound, thinking about money first is a big mistake and paralyses the entrepreneurial moves. Investors and successful entrepreneurs often laugh away concluding that one of the worst things that can happen to an entrepreneur is to have too much money too early! The Timmons model discounts the popular notion than extensive resources reduce the risk of starting a venture and encourages bootstrapping or starting with the bare minimal requirements as a way to attain competitive advantages. The advantages of bootstrapping include:

- Driving down market cost

- Instilling discipline and leanness in the organization

- Encouraging creative resources to achieve more with the limited amount of money and other resources available 
Some of the practical applications of such bootstrapping methods include leasing instead of buying equipment, working out of a garage instead of rented space, and the like. While good resources remain scarce, businesses with high potential opportunities and a good management team will have no problem attracting money and other resources. The entrepreneur works to "minimize and control" rather than "maximize and own." The role of the entrepreneur in managing the resources include building a good resource base to draw from when required and drawing up a business plan through a "fit and balance" method that balances the available resource with the opportunity and the potential of the team.

\section{Team}

A highly effective lead entrepreneur should be able to put the best talents together after identifying the opportunity and gathering required resources. The size and the background of the team are contingent upon the size and nature of opportunity. According to Timmons model, a good team can lead to great success and a badly formed team can waste great idea which is a disaster to any form of business. Among all resources, only a good team can unlock a higher potential with any opportunity and manage the pressures related to growth. The two major roles of the team, relative to the other critical factors are:

- Eliminating the ambiguity and uncertainty of the opportunity by applying creativity;

- Providing leadership to manage the available resources in the most effective manner by interacting with exogenous forces and the capital market context that keeps changing.

\section{Seeking the fit-and-balance}

Many entrepreneurs try to have all resources in place before starting a new venture. The Timmons model of entrepreneurship discounts this notion and holds only three factors, a market driven opportunity, availability of a good team and adequate resources as critical requirements before starting the venture. Maintaining the model of the above-mentioned three driving forces is the concept of fit and balance. Literally, Figure 1 depicts the important role of the lead entrepreneur or founder entrepreneur who needs to balance the three balls over his head, without toppling off. Such imagery is particularly helpful for one to acknowledge the urgency to retain the balancing act while getting all the elements matched.

The three critical factors of entrepreneurship remain interlinked, with any change in one factor having an impact on the other two. The reality is that opportunity, team, and resources seldom match and the Timmons model considers the major role of the entrepreneur to effect a match of the three critical factors of entrepreneurship at the correct time. Success of the business venture depends on the ability of the entrepreneur to ensure balance by applying creativity, leadership, and maintaining effective communications.

\section{RESEARCH METHODS}

A group of students signed up for the subject of Trade Logistics and Distribution in September 2017. This course divided the students into four classes. A total of sixteen groups of 4-5 students were assigned to implement an Entrepreneurial Logistics project. The groups were required to run a mini business project related to logistics. They prepared their business plans before starting their businesses. To get the business started, these students invested their own money. The amount of start-up capital varied from USD40 to USD150. Some of the groups involved themselves in selling commodities relevant to the university community made up by students, staff, and others who resided in the vicinity. These mini businesses lasted for two and a half months. The students acted as retailers, distributors, producers for the products or services that they had chosen. The profit they earned from the business ranged from USD4 to USD140, depending on the nature of the business and types of activities involved (Table 1). Students retained the profit among themselves. This experiential learning offered interesting 
and good experience for all the students because the execution and implementation of their business plan walked them through the entrepreneurial process.

After ending their mini businesses, these students were invited to fill in an evaluation form on the application of Timmons Model of Entrepreneurial Process. Besides collecting some demographic details such as gender, ethnicity, age and state of origin, these students were asked to rate on 18 statements concerning the six factors in Timmons model. Two statements each were formulated for opportunity, leadership and communication factor; three statements on team; four statements on resources and five statements on creativity. These statements were measured on the five Likert scale with 1 representing strongly disagree; $2=$ disagree, $3=$ neutral, 4 = agree and 5 = strongly agree. Students were assured that their responses would be kept private and confidential, used only for academic research purposes. These are the 18 statements posed to the students in relation to Timmons model:

1. A small team is better

2. The best number of team should not be more than five

3. Team members should be self disciplined

4. Group decision making is important

5. A good leader is required to ensure the success of the project

6. Resources should be shared equally

7. One of the problems faced is limited resources

8. Profit of the business is often over-estimated

9. Costs of operation are sometimes under-estimated

10. Communication is intensive among team members

11. Conflicts tend to arise among team members

12. Creative ideas are limited among team members

13. Creative ideas should be used to exploit such opportunities

14 . Business plan guides the project successfully

15. Various promotional activities should be carried out aggressively

16. Information technology can bring about more sales

17. Many business opportunities can be identified around UMK campus

18. There are many uncertainties faced by the business. 
Table 1 Nature of Business and Profit Earned

\begin{tabular}{|c|c|c|c|c|c|}
\hline & Group & Capital & Products/services & Point of logistics & Profit \\
\hline 1 & $\mid / 1$ & RM300 & Selling donuts/cakes & Retailer/product & RM120 \\
\hline 2 & $1 / 2$ & RM400 & Top up handphone & Retailer/service & RM95 \\
\hline 3 & $1 / 3$ & RM250 & Selling icecream/snacks & Retailer/product & RM215 \\
\hline 4 & $1 / 4$ & RM500 & Car rental & Retailer/service & RM425 \\
\hline 5 & $\| / 1$ & RM400 & Batik/garment sale & Retailer/product & RM307.5 \\
\hline 6 & $\| / 2$ & RM150 & Ironing & Retailer/service & RM24 \\
\hline 7 & $\| / 3$ & RM300 & Foods \& Beverages & Retailer/product & RM328 \\
\hline 8 & $\| / 4$ & RM360 & Mie, beehoon, kweetiau sale & Retailer/product & RM139 \\
\hline 9 & $\| / 1$ & RM450 & Craft making and sale & Producer\&Retailer/product & RM347 \\
\hline 10 & $11 / 2$ & RM300 & Top up handphone & Retailer/service & RM118 \\
\hline 11 & $11 / 3$ & RM400 & Provide late night food & Producer/service & RM196 \\
\hline 12 & $\| / 4$ & RM500 & Selling rice \& eggs & Retailer/product & RM267 \\
\hline 13 & IV/1 & RM600 & Electronics sale & Retailer/service & RM525 \\
\hline 14 & IV/2 & RM420 & Tursab \& other garment sale & Retailer/product & RM240 \\
\hline 15 & IV/3 & RM300 & Stationary sale & Retailer/product & RM186 \\
\hline 16 & IV/4 & RM200 & Ironing service & Retailer/service & RM62 \\
\hline
\end{tabular}




\section{RESULTS AND FINDINGS}

A total of 73 students participated in this study. To ensure the consistency in the measures used, reliability test was run on the 18 statements. Cronbach alpha was found to be 0.673 and this implies that the constructs designed by the study can be considered reliable. Descriptive analysis was run to compile respondents' demographic details and this can be seen in Table 2 .

Table 2 Characteristics of respondents

\begin{tabular}{|l|c|}
\hline Item & Frequencies \\
\hline Gender & 25 \\
Male & 48 \\
Female & 50 \\
\hline Age & 23 \\
Below 22 years old & \\
Above 22 years old & 62 \\
\hline Ethnicity & 3 \\
Malay & 8 \\
Chinese & \\
Indian & 4 \\
\hline State of Origin & 7 \\
Malacca & 8 \\
Penang & 9 \\
Pahang & 14 \\
Johore & 3 \\
Kelantan & 1 \\
Sarawak & 4 \\
Sabah & 6 \\
Perak & 2 \\
Wilayah Persekutuan & 12 \\
Terengganu & 2 \\
Selangor & 1 \\
Kedah & \\
Negeri Sembilan & \\
\hline
\end{tabular}

To achieve the first objective of this research, researchers conducted descriptive analysis by computing the mean scores for all of the six factors in Timmons Model of Entrepreneurial Process. As shown in Table 3, resource availability ranked as the most important factor with the mean score reported at 4.7705 , and this is followed by creativity with its mean score of 4.6767 and thirdly, leadership quality with the mean score of 4.4658 . 
Table 3 Computation of Mean for Six Factors in Timmons Model

\begin{tabular}{|l|c|c|c|c|c|}
\hline & $\mathrm{N}$ & Minimum & Maximum & Mean & $\begin{array}{c}\text { Std. } \\
\text { Deviation }\end{array}$ \\
\hline Team & 73 & 3.00 & 5.00 & 4.2146 & .54254 \\
\hline Leadership & 73 & 2.50 & 5.00 & $\mathbf{4 . 4 6 5 8}$ & .54854 \\
\hline Resources & 73 & 4.00 & 5.75 & $\mathbf{4 . 7 7 0 5}$ & .50647 \\
\hline Communication & 73 & 1.00 & 5.00 & 3.3836 & .65363 \\
\hline Creativity & 73 & 3.60 & 5.80 & $\mathbf{4 . 6 7 6 7}$ & .48262 \\
\hline Opportunity & 73 & 2.00 & 5.00 & 3.7945 & .64461 \\
\hline
\end{tabular}

The second objective was fulfilled by running correlation analysis. Table 4 shows that creativity is significantly related to all other factors except for communication. Interestingly, opportunity identification was found to be significantly related to creativity at p-value less than 0.05 and coefficient of 0.284 . Creativity is significantly related to team factor with p-value less than 0.05 and its correlation coefficient reported at 0.276 . There is also a significant relationship between leadership quality and creativity with p-value recorded at less than 0.01 and correlation coefficient of 0.330 . Resources availability is also significantly related to creativity at p-value less than 0.5 and coefficient of 0.295 . Lastly, leadership quality was found to be significantly related to resources availability at a p-value of less than 0.5 and correlation coefficient of 0.240 .

Table 4 Correlations

\begin{tabular}{|c|c|c|c|c|c|c|}
\hline & & Opportunilv & Resources & Team & Leadership & Crealivily \\
\hline \multirow{3}{*}{ Resources } & Pearson Correlation & .034 & & & & \\
\hline & Sig. (2-lailed) & .773 & & & & \\
\hline & $\mathrm{N}$ & 73 & & & & \\
\hline \multirow[t]{3}{*}{ Team } & Pearson Correlation & .214 & .004 & & & \\
\hline & Sig. (2-tailed) & .069 & .976 & & & \\
\hline & $\mathrm{N}$ & 73 & 73 & & & \\
\hline \multirow[t]{3}{*}{ Leadership } & Pearson Correlation & .196 & $.240^{\circ}$ & 196 & & \\
\hline & Sig. (2-tailed) & .097 & .041 & .096 & & \\
\hline & $\mathrm{N}$ & 73 & 73 & 73 & & \\
\hline \multirow[t]{3}{*}{ Creativity } & Pearson Correlation & $.284^{*}$ & $.295^{*}$ & $.276^{*}$ & $.330^{* *}$ & \\
\hline & Sig. (2-lailed) & .015 & .011 & .018 & .004 & \\
\hline & $\mathrm{N}$ & 73 & 73 & 73 & 73 & \\
\hline \multirow[t]{3}{*}{ Communication } & Pearson Correlation & .033 & -.092 & .065 & -.060 & .126 \\
\hline & Sig. (2-tailed) & .781 & .437 & .585 & .616 & .290 \\
\hline & $\mathrm{N}$ & 73 & 73 & 73 & 73 & 73 \\
\hline
\end{tabular}

*. Correlation is significant at the 0.05 level (2-tailed)

**. Correlation is significant at the 0.01 level (2-tailed).

\section{DISCUSSION AND CONCLUSION}

Based on the above findings, it can be concluded that students of UMK, having implemented mini business project in group, agree with Timmons model that resource availability is one of the critical factors determining the business success. Surprisingly, contrary to what has been suggested by Timmons, the three critical factors perceived to be important by this batch of students are resource availability, creativity and leadership quality. Such findings could be attributed to the nature of this mini business project which requires them to work in a group. On the other hand, students concluded that the level of creativity in the group is significantly related to all factors except for communication. This implies that level of creativity could be a determining factor for opportunity identification, resource availability, leadership quality and teamwork. 
This findings could be attributed to Hofstede (1991) study which asserts that Malaysians tend to favour collectivism as opposed to individualism. Although Timmons model bases the entrepreneurial process to individual effort where the key of success lies with the founder or entrepreneur, students at this stage felt that in order for them to be successful in their business, they need to gather enough resources, be creative and have a good leader in the team. The need for collective effort is further strengthened when the result of correlation indicates that students' creativity is contingent upon the opportunity they identify as a group, resource they could gather together, the effective leadership and cooperative team effort. In other words, students' responses were somehow skewed to the collective effort they longed for in running the mini business project.

There is little dispute today that entrepreneurial team is a key ingredient in the higher potential venture. Famous investor Arthur Rock expressed that importance of team over a decade ago (Rock, 1987). He said, "If you can have good people, they can always change the product. Nearly every mistake I have made has been I picked the wrong people, not the wrong idea". In today's world, we are blessed with plenty of technology, plenty of entrepreneurs, plenty of money, plenty of venture capital. What we do not have in great teams (Fast Company, 1997). Thus, the biggest challenge is building a great team under effective leadership, as perceived by students participated in this study. Timmons et al. (2004) stipulated the importance of having good team under great leadership by summarising the following points:

An entrepreneurial leader

- Learns and teaches - faster, better

- Deals with adversity, is resilient

- Exhibits integrity, dependability, honesty

- Builds entrepreneurial culture and organization

Quality of the team fulfils the following criteria:

- Relevant experience and track record

- Motivation to excel

- Commitment, determination and persistence

- Tolerance of risk, ambiguity and uncertainty

- Creativity

- Team focus of control

- Adaptability

- Opportunity obsession

- Leadership

- Communication

\section{LIMITATIONS AND FUTURE RESEARCH}

This research study is not without any weaknesses. Firstly, having only 73 students to participate in this study amounted to a sample that can be argued to be rather smaller. Therefore, findings could not be generalized to the full context of UMK students. Secondly, the students being experimented are confined to only those who undertook the subject of Trade Logistics and Distribution. Hence, the generalizability of findings to students of other courses could be questionable. Lastly, since the data originates from students studying in UMK, the researchers could not conclude the same for all other universities. Due to these limitations, the researcher recommends that future research be conducted to increase the sample size for a better validation. Further studies may also include all students in UMK, not confining it only to Trade Logistic and Distribution students. Similar theoretical framework should be tested on 
other universities, both private or public, so as to reaffirm the findings compiled in this research study.

\section{References}

Doerr, J. (1997). Start-Up Manual. Fast Company, February - March, p. 82-84.

Fast Company, February - March, 1997, p. 84.

Hofstede, G. (1991). Managing in a cultural society. Malaysian Management Review, 29, 3-12.

Hofstede, G. (1997). Cultures and Organizations: Software of the Mind. New York: McGraw-Hill.

Hofstede, G. (2001). Culture's Consequences: Comparing Values, Behaviours, Institutions and Organizations Across Nations. Thousand Oaks, CA: Sage Publications.

Nayab, N. (2010). Timmons Model of Entrepreneurship. Accessible Online.

Rock, A. (1987). Strategy vs tactics from a venture capitalist. Harvard Business Review, November - December, p.63-67.

Timmons, J. And Spinelli, S. (2009). New Venture Creation. McGraw-Hill: New York.

Timmons, J., Zacharakis, A., and Spinelli, S. (2004). Business plans that work: A guide for small business. McGrawHill. 